\title{
Learning curve for laparoscopic Roux-en-Y gastric bypass based on the experience of a newly created bariatric center
}

\author{
Wkład autorów: \\ A-Projekt badań \\ B-Zbieranie danych \\ C-Analiza statystyczna \\ D-Interpretacja danych \\ F-Analiza literatury \\ Jadwiga Dworak ${ }^{\mathrm{ABCDEF}}$, Michał Wysocki ${ }^{\mathrm{ABF}}$, Anna Rzepa ${ }^{\mathrm{BDE}}$, Michał Pędziwiatr $^{\mathrm{DE}}$, \\ Dorota Radkowiak $^{\mathrm{BC}}$, Andrzej Budzyński $^{\mathrm{AD}}$, Piotr Major ${ }^{\mathrm{ADE}}$ \\ 2nd Department of Ceneral Surgery, Jagiellonian University Medical College, Cracow, Poland
}

Article history: Received: 28.12.2018 Accepted: 20.05.2020 Published: 21.05.2020

ABSTRACT:

Introduction: Laparoscopic Roux-en-Y gastric bypass (LRYCB) is one of the most common treatments for morbid obesity. The learning curve for this procedure is 50-75 cases for an independent surgeon, and it is considered the most important factor in decreasing complications and mortality. We present our experience and learning curve with LRYCB for a newly established bariatric center in Poland.

Material and methods: A prospectively collected database containing 285 LRYCB procedures performed in the II Department of Ceneral Surgery of the Jagiellonian University MC in Krakow between 06.2010 and 03.2019 was retrospectively reviewed. Patients were divided into groups of $30\left(\mathrm{G}_{1}-\mathrm{C}_{10}\right)$ in the order of the procedures performed by each surgeon. The study analyzed the course of the operation and patient hospitalization, comparing those groups. Learning curve for the newly created bariatric center was established.

Results: Operative time in $\mathrm{G}_{1}-\mathrm{C}_{3}$ differed significantly from $\mathrm{G}_{4}-\mathrm{G}_{10}(\mathrm{P}<0.0001)$. The stabilization point was the $90^{\text {th }}$ procedure. Perioperative complications were observed in $36(12.63 \%)$ patients. Perioperative complications, intraoperative difficulties and adverse events did not differ importantly among groups. Liberal use of "conversions of the operator" from a surgeon to a senior surgeon provides reasonable safety and prevents complications.

Conclusions: The institutional learning process stabilization point for LRYCB in a newly established bariatric center is around the 9oth operation. LRYCB can be a safe procedure from the very beginning in newly established bariatric centers. Specific bariatric training with active proctoring by an experienced surgeon in a bariatric centre can improve the laparoscopic gastric bypass outcome during the learning curve.

KEYWORDS: $\quad$ bariatric center, clinical competence, laparoscopic Roux-en-Y gastric bypass, learning curve, perioperative complications, surgical training

\section{ABBREVIATIONS}

BMI - body mass index

CI - confidence interval

ERAS - Enhanced Recovery after Surgery

GJ - gastrojejunostomy

IQR - interquartile range

J - jejunojejunostomy

LC - learning curve

LRYGB - laparoscopic Roux-en-Y gastric bypass

OR - odds ratio

OT - operative time

SD - standard deviation

T2DM - type 2 diabetes mellitus

\section{INTRODUCTION}

Obesity has become one of the biggest global healthcare problems. Worldwide obesity has nearly tripled since 1975. In 2016, the World Health Organization described more than 1.9 billion adults, which makes up to $39 \%$ of the global adult population, as overweight, and over 650 million as obese, which makes $13 \%$ of the global adult population [1]. An even worse trend can be observed in Poland, where $54.7 \%$ of adults in 2014 were overweight and $17.2 \%$ were obese [2]. Excess weight is associated with a drastic increase of one's risk of developing a number of non-communicable diseases, like: type 2 diabetes mellitus (T2DM), hypertension, dyslipidaemia, non-alcoholic steatohepatitis, stroke, sleep apnea, cancer, and other serious comorbidities [3]. A systematic review and meta-analysis focusing on the association of all-cause mortality with overweight and obesity showed that, relative to normal weight, obesity was associated with a significantly higher all-cause mortality [4]. To date, bariatric surgery has proven itself to be the most effective modality to treat morbidly obese patients and the only sustainable solution to reduce weight with mid- and long-term control and to diminish accompanying comorbidities in this patient group [5]. The increasing demand for bariatric surgery is a heavy burden on health care facilities and emphasizes the need for training of new bariatric surgeons and institutes. Currently, the laparoscopic Roux-en-Y gastric bypass (LRYGB) is one of the most commonly performed bariatric procedures. It is a technically challenging operation with a high risk of severe morbidity and mortality [6] and with a learning curve (LC) of 50 to 75 cases for an independent surgeon [7]. The LC is the number of procedures that need to be performed to master the procedure. The concept of $\mathrm{LC}$ is based on the premise that people become better at their task with repetition and LC can be defined by operating time and by complications [8]. There were some studies covering the topic of LC in LRYGB, unfortunately, most of those studies involved series of consecutive patients treated by expert bariatric surgeons who already passed their learning curve or by surgeons during their formal bariatric training in centers of excellence $[9,10]$. 
In this study, we investigated the learning curve of LRYGB in a newly created bariatric center in Poland. The main goal was to assess the course of operation and patient hospitalization during the learning curve for the newly established bariatric center.

\section{MATERIAL AND METHODS}

We collected the data of patients subjected to surgical treatment of morbid obesity in the Second Department of General Surgery, Jagiellonian University Medical College (academic teaching hospital, tertiary referral center for general surgery and newly established bariatric center). Retrospective analysis of the data was performed. Criteria for surgical treatment were in accordance with the guidelines of the Metabolic and Bariatric Surgery Section of the Polish Surgical Society (i.e., body mass index [BMI] $\geq 35 \mathrm{~kg} / \mathrm{m}^{2}$ with obesity comorbidities or BMI $\left.\geq 40 \mathrm{~kg} / \mathrm{m}^{2}\right)$. The inclusion criteria were as follows: willingness to participate voluntarily in the study and giving written consent for participation, age 18-65, fulfilling the eligibility criteria for bariatric treatment, qualification for LRYGB. Patients were excluded from the study if: undergoing revision surgery or surgery other than LRYGB, diagnosed with a mental illness or addicted to drugs or alcohol. The flow of patients through the study is shown in Fig. 1.

The bariatric team that performed the surgeries comprised of one senior surgeon, four attending surgeons and two surgery residents in their fourth year of training, who became specialists during the analyzed period. Introduction of bariatric procedures was structured. Initially, a senior surgeon visited high-volume bariatric centers to participate in bariatric internships. Procedures then started in the department along with the introduction of a treatment protocol. Guest surgeons from high-volume bariatric centers proctored the learning process in the bariatric team in the first 15 cases of LRYGB during 2 weeks. The requirements for operators were: acquirement of an appropriate theoretical background in bariatric surgery, prior experience in laparoscopic surgery (including structured training on simulators), and assistance to at least 15 LRYGB. First 10 procedures for all operators were performed under proctorship of a senior experienced surgeon. We defined the number of 30 operations as a basic unit for further analysis.

Patient care was standardized in accordance with the principles of the multimodal Enhanced Recovery after Surgery (ERAS) pathway, as described elsewhere [11-13]. Patients were evaluated by a respective surgeon and a psychologist to determine patient's candidacy for LRYGB. All patients included in this study were scheduled to undergo LRYGB and were operated on after giving written informed consent. The operative technique was changed a few times during the analyzed period but it always consisted of a completely stapled jejunojejunostomy (JJ) with retrocolic path of the alimentary limb of varying lengths, a stapled gastric pouch of 20-30 mL in volume with a linear-stapled gastrojejunostomy (GJ).

The analyzed group was divided into subgroups according to the order of the procedure performed by each surgeon:

- G1, group number 1 (1st-30th LRYGB);

- G2, group number 2 (31st-60th LRYGB);

- G3, group number 3 (61st-90th LRYGB);

- G4, group number 4 (91st-120th LRYGB);
- G5, group number 5 (121st-150th LRYGB);

- G6, group number 6 (151st-180th LRYGB);

- G7, group number 7 (181st-210th LRYGB);

- G8, group number 8 (211th-240th LRYGB);

- G9, group number 9 (241st-270th LRYGB);

- G10, group number 10 (271st-285th LRYGB).

The primary endpoint was determining the stabilization point of the LRYGB learning curve in each group using operative time and perioperative complications. As secondary endpoints, the effects of the learning curve on intraoperative difficulties, intraoperative adverse events, conversion of the operator, reoperation rate, readmission rate, conversion rate and 30-day mortality rate were assessed.

If the operation was completed by a different person than the one who started the procedure we referred to this as "conversion of the operator". The reasons for such conversions were: lack of progress in the procedure, anatomical difficulties imposing a high risk of complications, intraoperative adverse events. In case of the residents, the supervising surgeon was taking over the operation. Similarly among patients operated on by attending surgeons, conversions of the operator to the senior surgeon with the highest expertise in LRYGB were included in the analysis. Number and reasons for such conversions of the operator were assessed.

Directly after each procedure, every main operator was obligated to note down the intraoperative difficulties, which were defined as surgeon-reported obstacles during the operation. The surgeon had to introduce all the reported obstacles in the LRYGB Matrix Table Questionnaire. The table consisted of the following groups: difficulty of proper setting the stapler or in swing (pouch/anastomosis), difficulty in proper dissection, difficulty with bowel mobilization, intra-abdominal adhesions obstructing performance of surgery, difficulty to achieve good and sufficient working space and the need for assistance from a supervisor (conversion of the operator).

Intraoperative adverse events were defined as any iatrogenic adverse events during surgery which were not derived from the standard LRYGB technique. Perioperative complications were defined as adverse events occurring within 30 days after the procedure. Major complications were defined as grade III or higher in the ClavienDindo classification [14]. Rhabdomyolysis was defined as an elevated serum creatine phosphokinase concentration of $>1000 \mathrm{U} / \mathrm{L}$ with a concomitant increase in myoglobin concentrations. The operative time was measured from the skin incision to its closure.

In the period from June 2010 to March 2019, 970 patients underwent massive obesity treatment in the II Department of General Surgery of the Jagiellonian University Medical College. In the group of patients qualified for surgery who met the inclusion criteria there were 285 patients (165 women, 120 men, the mean age $46.99 \pm 9.90$ years). The characteristics of those patients are presented in Tab. I.

All data were analyzed with Statsoft Statistica version 12.0 PL (StatSoft Inc., Tulsa, OK, USA). The results are presented as mean \pm standard deviation (SD), median and interquartile range, and odds ratios (ORs) with 95\% confidence intervals (CIs) when appropriate. Tests were used according to the type of the variable. In order to assess the statistical significance of the observed differences in the frequency among groups in the qualitative data, a chi-square test 
with the Yates correction was used. The linear regression model was used to analyze the quantitative variables. The one-way logistic regression was carried out to calculate the odds ratio with a $95 \%$ confidence interval. Results were considered statistically significant when the P value was less than 0.05 .

All procedures performed in studies involving human participants were in accordance with the ethical standards of the Bioethics Committee of the Jagiellonian University (KBET/62/B/2011) and with the 1964 Helsinki declaration and its later amendments.

\section{RESULTS}

The median operative time for LRYGB was 130 (105-170) minutes. The Kruskal-Wallis ANOVA showed that there was a significant difference in the median operative time among the groups $(\mathrm{P}<0.0001)$ (Tab. II.). Multiple comparisons of the median ranges for all groups showed significant differences between G1-G3 and G4-G10. Based on multiple comparisons of the median range tests, the LRYGB learning curve stabilization point was the 90th procedure for the whole newly established bariatric center (Fig. 2.).

Perioperative complications were observed in 36 (12.63\%) patients. There were 19 patients with perioperative complications of ClavienDindo class I, 3 patients with class II, 10 patients with class III, 2 patients with class IV and 2 patients with class V. Detailed characteristics of perioperative morbidity regarding ClavienDindo scale is presented in Tab. III. The most common complication overall was rhabdomyolysis [17 (5.96\%)]. The difference in the ratio of perioperative complications among the groups was not statistically significant $(\mathrm{P}=0.4158)$. Based on perioperative morbidity, there is no possibility to assess the learning curve for LRYGB. During the whole process of reaching the learning curve plateau procedures were performed in similarly safe manner.

Reoperations were necessary in 11 (3.86\%) patients. Four reoperations were performed due to gastrointestinal leak (2 times on account of leakage from anastomosis and 2 times because of iatrogenic perforation of the bowel), 2 - due to strangulated hernia (one in the previous umbilical hernia and one in the trocar wound), 3 - on account of stapler line bleeding, 1 - because of intraabdominal abscess and 1 - due to necrosis of greater omentum. This parameter could not be used for setting the stabilization point.

Seven patients were readmitted on account of complications after discharge. Five of them needed reoperation ( 2 - because of strangulated hernia, 1 - due to surgical site infection and necrosis of greater omentum, 2 - on account of anastomotic leakage). One readmission was because of acute kidney injury and another due to pulmonary embolism; there was no need for surgical intervention in either of the cases.

In the analyzed period two patients died due to perioperative complications. One patient developed severe peritonitis from bowel necrosis and perforation following hernia strangulation. The other one died on the 1 . day after surgery due to a massive pulmonary embolism.

The incidence of intraoperative difficulties, which were based on the operators' subjective opinion, was similar in all groups

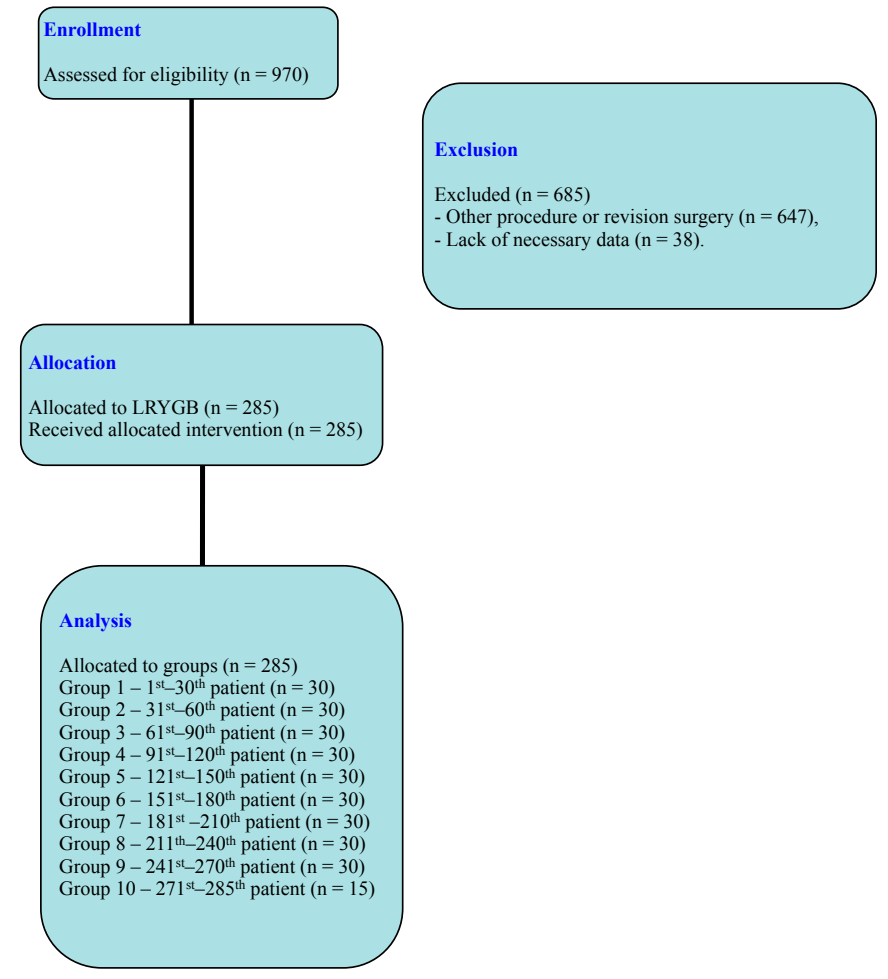

Fig. 1. Study flow chart.

$(\mathrm{P}=0.5471)$. There were 39 intraoperative difficulties reported on. In case of 9 patients, conversion of an operator was needed (23.08\% of all intraoperative difficulties). According to these results, there is no possibility to use intraoperative difficulties as a factor to determine the learning curve of LRYGB. All intraoperative difficulties are shown in Tab. II.

We identified 9 cases (3.16\% of all LRYGBs) of conversion of the operator - situation when the operator could not safely complete the procedure. In 4 cases, the conversion of the operator was due to difficulties with anastomosis formation. In 3 cases we found a description "difficulty in proper setting of the stapler" or "difficulty in gastric pouch formation" in the operation reports as the possible cause of conversion of the operator. In the remaining 2 cases, difficulty of bowel mobilization and "too short and too thick mesentery" were the reason for operator conversion.

Intraoperative adverse events were observed during 18 (6.32\%) operations (Tab. II.). The most common intraoperative adverse events were bowel injury and improper anastomosis. The overall ratio of intraoperative adverse events was similar in all groups $(\mathrm{P}=0.8796)$. Similarly, to intraoperative difficulties and conversions of the operator, there is no possibility to use intraoperative adverse events as a factor to determine the learning curve of LRYGB.

There was no conversion to open surgery, all procedures were completed laparoscopically.

\section{DISCUSSION}

The increasing number of morbidly obese patients worldwide creates a high demand for bariatric surgery. Therefore, the interest in bariatric training programs increases. Minimally invasive bariatric 


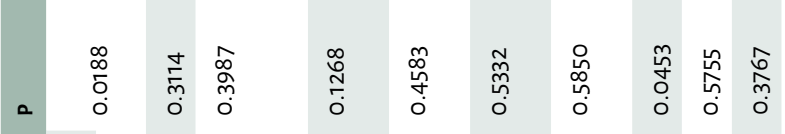

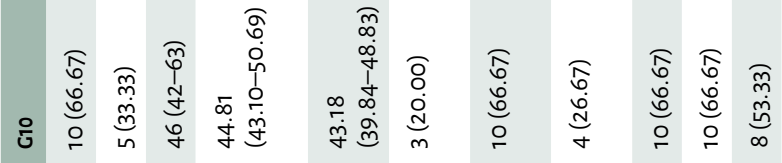

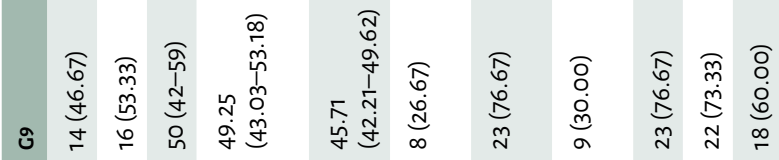

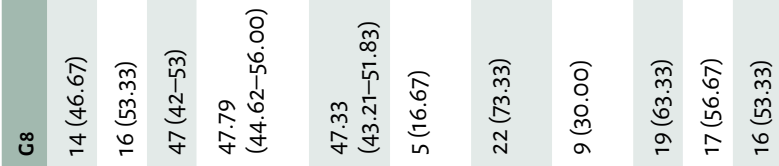

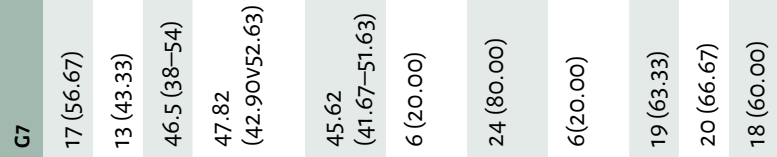

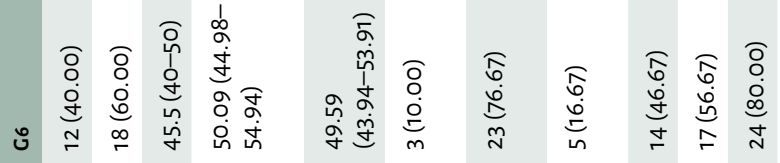

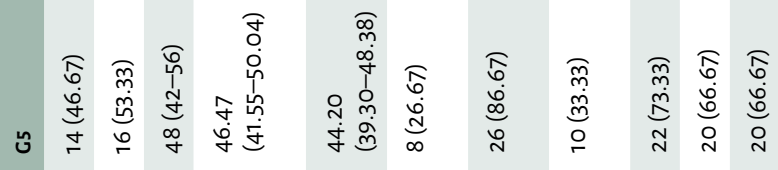

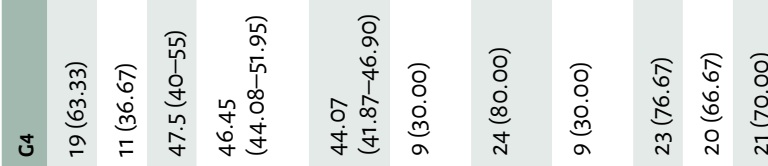

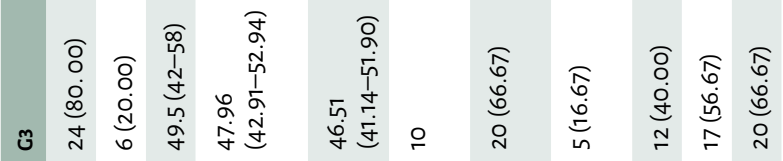

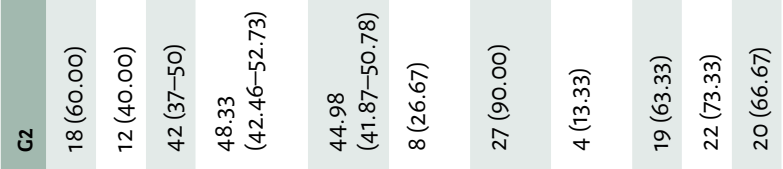

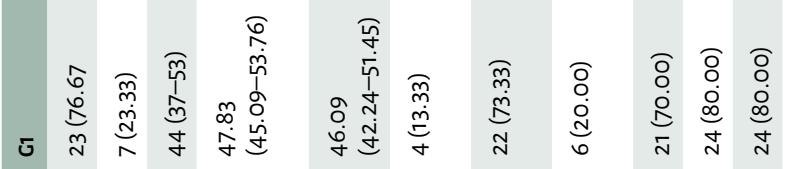

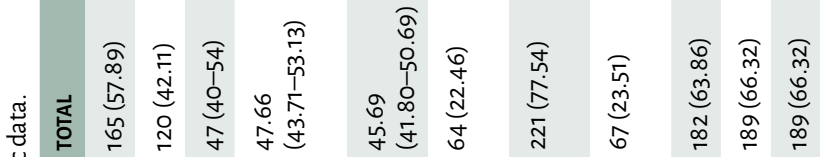

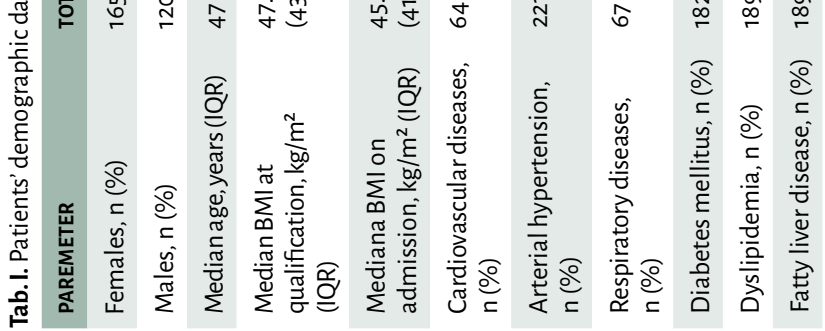

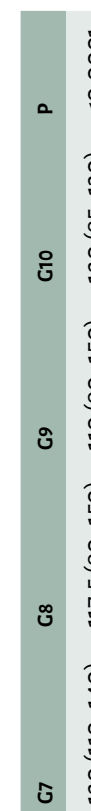

0
$\swarrow$
$\infty$
0
0

ำ 옹

งิ $\stackrel{\circ}{=}$

ษ $\stackrel{2}{\simeq}$

ษ

แ ปู่

ษ $\stackrel{\circ}{\stackrel{2}{\circ}}$

\%

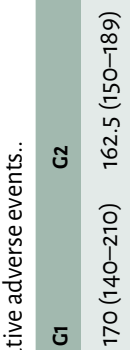

ธ

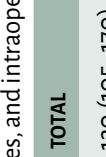

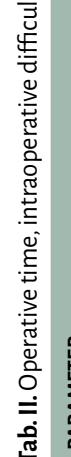

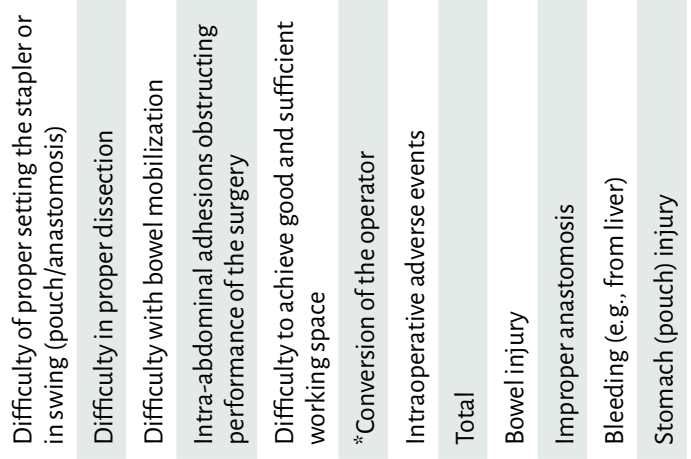


surgery in Poland is still a developing discipline. Most studies worldwide have shown that $50-75$ patients must be treated by one surgeon for him/her to overcome the learning curve and master this procedure. These results were derived from large volume bariatric centers $[7,9,10]$. The literature reports that lower mortality, conversion, and major complication rates can be achieved with fellowship-trained bariatric surgeons [17] or high-volume bariatric centers [6]. The learning curve for LRYGB in low volumes or newly established bariatric units has presented a challenge for beginners [15].

We describe a 9-year experience with LRYGB in the Second Department of General Surgery Jagiellonian University Medical College - newly established bariatric center. We aimed to assess our institutional learning process for LRYGB and the effect of this process on safety and perioperative complications.

Operative time is frequently regarded as a descriptive parameter for evaluating the learning curve. In our study, the operative time (OT) was a mean of $130 \mathrm{~min}$. In the first 30 operations (group 1) OT was around $170 \mathrm{~min}$ and was getting shorter with repetition, reaching $120 \mathrm{~min}$ in group 4 . Zevin et al. reviewed 12 series and showed that OT ranged from 113 minutes to 324 minutes in the late learning period [18]. Shih-Chiang et al. showed that for a newly established bariatric unit OT was $120 \mathrm{~min}$ for the first 30 operations and around $80 \mathrm{~min}$ for the next 30 procedures [15]. Shin et al. showed the mean OT of 73 minutes after 50 cases demonstrates that a surgeon with advanced laparoscopic skills can acquire the necessary technical expertise in performing LRYGB after 50 cases [7]. Geubbels et al. mentioned a sudden decrease in OT with every subsequent surgeon in the first 50 cases and a decrease in OT with the first 150 cases for all individual operators. He added that some surgeons benefit directly from the experience already gained by more experienced colleagues and then "learn to operate faster". Furthermore, according to Geubbels, institutional experience grew parallel to individual experience over the course of time. He confirmed surgical experience as the primary explanation of OT decrease. Although he emphasized that although the decrease in OT after every 50 cases is indeed well explained by the increase in experience, the differences among the surgeons are not [16]. Taking into account these results we can assume that probably our longer OT (as compared to most of the previous studies) is connected with no previous experience in bariatric surgery and low volume of our unit. Despite all this, we reached the limit of mean OT equal to $120 \mathrm{~min}$, which was established as the stabilization point of LRYGB LC by Oliak [17].

In our study, perioperative complications were observed in 36 (12.63\%) patients. There were only 14 (4.91\%) severe complications (Clavien-Dindo class III and more). The most common complication was rhabdomyolysis - 17 (5.96\%). The difference in the rate of perioperative complications among the groups was not statistically significant, which means that during the whole process of reaching the learning curve plateau, the procedures were performed in a similarly safe manner. These results are different than with other authors. Shih-Chiang et al. noticed a significant difference in the complication rate during LC achievement (26.7\% in the first group and $6.7 \%$ in the second group) [15]. Sánchez-Santos et al. in the systematic review concerning the influence of a training program in the LC of LRYGB for morbid obesity informed that the overall complication rate in LRYGB ranges from $5 \%$ to $36 \%$. He showed

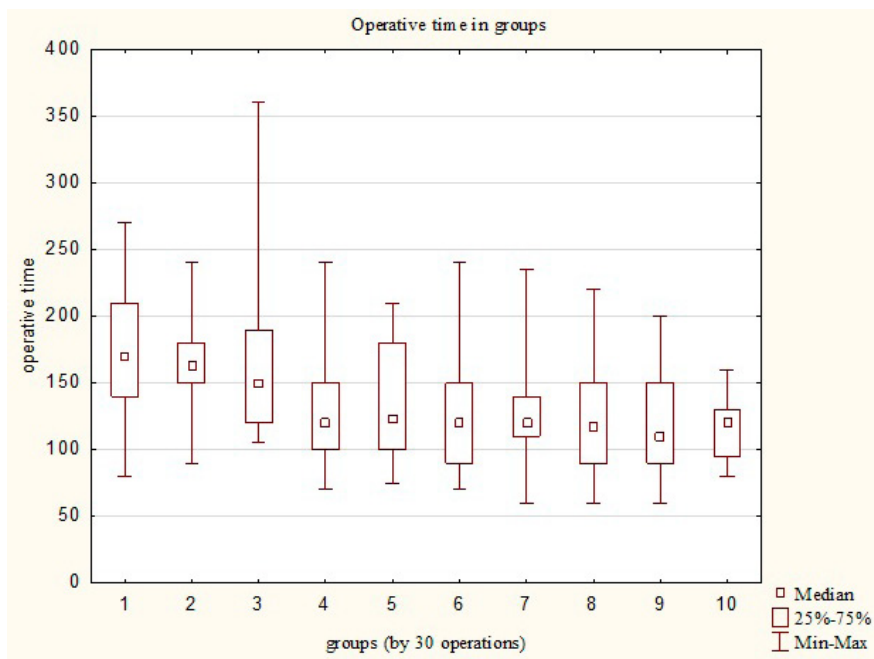

Fig. 2. Operative time in groups.

also that surgeons with training in laparoscopic bariatric surgery, as compared to those without training, had a much lower complication rate (7.7 \% versus $18.1 \%$ ) [9]. El-Kadre et al. showed the overall prevalence of early postoperative complications equal to $1.75 \%$, which seems to be very low compared to other researchers [19]. Sommer et al. also showed a very low complication rate, i.e. $2-3 \%$. He concluded that the main reason for the low complication rate is the high volume of the clinic, with up to 12 LRYGBs per day, and the training program giving the possibility of doing the same operation every day within a limited timeframe ("it was possible for the trainee to remember and correct yesterday's faults, thus acquiring the abilities to perform the procedure in a fast and safe way") [20]. Several factors, besides advanced laparoscopic skills, may be responsible for the overall low complication rate. Joining an experienced surgeon with an existing high-volume bariatric surgical practice, having extensive proctorship, dedicated surgical assistance, and a high volume for a novice bariatric surgeon probably lead to shortening of the learning curve. Evidence has shown lower complication rates in hospitals with high annual volumes and a lot of institutional experience [16]. When looking only at complications of surgical etiology of any surgeon, no learning curve seems apparent. This might reflect the learning curve of a centre (in detecting and handling symptoms of complications) rather than the learning curve of an individual surgeon. Evidence showed that when less experienced surgeons operate in a centre with extensive bariatric experience, under proctorship of an experienced bariatric surgeon and with applied patient selection, their outcomes are comparable to those of more experienced colleagues [16]. Even though our bariatric center is newly established and low volume, our results are similar to those described elsewhere $[9,15]$. Such nearly successful outcomes were probably due to the adoption of preventive measures associated with ERAS protocol implementation and the presence of experienced proctors trained in bariatric surgery.

Reoperations were necessary in 11 (3.86\%) patients. The result is similar to the one of other authors, for example Søvik TT et al. reported 4.8\% [21]. According to our calculation, this parameter could not be a factor determining LC of LRYGB.

Seven patients were readmitted due to complications after discharge. Two patients died during the 30-day postoperative period. There were 9 cases of conversion of the operator. Eleven intraoperative adverse events were observed. There was no 
Tab. III. Perioperative ( $\leq 30$ days) morbidity regarding Clavien-Dindo scale and reoperations.

\begin{tabular}{|c|c|c|c|c|c|c|c|c|c|c|c|c|c|}
\hline C-D & COMPLICATIONS & No. & G1 & G2 & G3 & C4 & G5 & G6 & G7 & G8 & C9 & G10 & P-VALUE \\
\hline & Total & 36 & 4 & 6 & 6 & 4 & 6 & 4 & 2 & 1 & 2 & 1 & 0.4158 \\
\hline 5 & Death & 2 & 0 & 2 & 0 & 0 & 0 & 0 & 0 & 0 & 0 & 0 & \\
\hline 4 & Need of ICU (ARDS) & 2 & 1 & 0 & 0 & 0 & 0 & 1 & 0 & 0 & 0 & 0 & \\
\hline \multirow[t]{4}{*}{$3 b$} & Strangulated hernia (reoperation) & $1(2)$ & 0 & $\circ(1)$ & 0 & 1 & 0 & 0 & 0 & 0 & 0 & 0 & \\
\hline & GI leak (reoperation) & 4 & 0 & 0 & 0 & 0 & 0 & 1 & 1 & 0 & 1 & 1 & \\
\hline & Operation site bleeding (reoperation) & 3 & 0 & 0 & 1 & 1 & 0 & 0 & 0 & 1 & 0 & 0 & \\
\hline & $\begin{array}{l}\text { Surgical site infection and necrosis of } \\
\text { greater omentum (reoperation) }\end{array}$ & 2 & 0 & 0 & 0 & 1 & 0 & o & 0 & 0 & 1 & 0 & \\
\hline \multirow[t]{3}{*}{2} & pulmonary embolism & $1(2)$ & 0 & $\circ(1)$ & 0 & 0 & 0 & 0 & 1 & 0 & 0 & 0 & \\
\hline & pneumonia & $1(2)$ & $1(2)$ & 0 & 0 & 0 & 0 & 0 & 0 & 0 & 0 & 0 & \\
\hline & AKI & $1(2)$ & 0 & $\circ(1)$ & 0 & 0 & 1 & 0 & 0 & 0 & 0 & 0 & \\
\hline \multirow[t]{3}{*}{1} & Gastroparesis & 1 & 0 & 0 & 0 & 0 & 0 & 1 & 0 & 0 & 0 & 0 & \\
\hline & Fever of unknown origin & 1 & 0 & o & 1 & 0 & 0 & 0 & 0 & 0 & o & 0 & \\
\hline & Rhabdomyolysis & $17(18)$ & 2 & $4(1)$ & 4 & 1 & 5 & 1 & 0 & 0 & 0 & 0 & \\
\hline
\end{tabular}

If more than 1 complication occurred in the same patient only the one with a higher grade was taken into the calculation; lower complications are added in brackets.

C-D-Clavien-Dindo classification grade; $\mathrm{Cl}$ - gastrointestinal, AKI - acute kidney injury, ICU-intensive care unit.

conversion to open surgery. Similarly, to reoperation rate there was no possibility to use 30-day mortality rate, conversions of the operator, intraoperative adverse events or conversions to open surgery as factors to determine learning curve of LRYGB.

We reported intraoperative difficulties during 39 (13.68\%) procedures. In our study there was no correlation with incidence of intraoperative difficulties and LC. Unfortunately, we could not find any previously published studies regarding intraoperative difficulties in LRYGB, which seem to be important parameters for assessment of the learning curve $[22,23]$.

Usually, a learning curve is evaluated using selected parameters for particular surgeon. We assessed the institutional learning process using intraoperative difficulties, perioperative morbidity, and OT, while obtaining accurate results. OT of the first 90 procedures was significantly longer than that of the next 195 surgeries. The median OT in the group 4 (91st-120th LRYGB) was equal $120 \mathrm{~min}$, so according to reviews of Oliak [17] LC was reached after 90th LRYGB. According to these reviews [17] nearly from very beginning LC for LRYGB was overcame when perioperative complications were taking into account: mortality rate was equal $0.6 \%(<1 \%)$, conversion rate was $0 \%(1-3 \%)$, major morbidity was $5.95 \%(<5 \%)$, major leak rate was $1.40 \%(<2 \%)$. Based on all that, the institutional learning process stabilization point was after 90th procedure for the whole newly established bariatric center.

In our study there was no possibility to assess LC of LRYGB by: intraoperative difficulties, perioperative morbidity rate, 30-day mortality rate, conversions of the operator, intraoperative adverse event rate, number of conversions to open surgery nor reoperation rate. The result is very satisfactory and shows that LRYGB can be a safe procedure from the very beginning in a newly established bariatric center.

Like any study with a retrospective nature, this study has several limitations. Our institution is a referral center for general surgery and a teaching hospital. Therefore, our results probably cannot be extrapolated to all hospitals. The learning curve defined by both complication rate and OT is also partly dependent on factors which could not be accounted for in this study. As described in the methods section, changes in surgical technique were made during the course of the study. These technical modifications certainly confounded OT as well as outcome measures. Another limitation of this study is the applied patient selection (on sex, BMI, age, comorbidities), which might bias outcomes. A larger amount of operated patients would enable the use of all of the parameters we attempted to test for describing the learning curve. Maybe the results will follow these of El Kadre et al.: that operating time and risk of adverse outcome were significantly reduced after a long learning curve of 500 consecutive procedures [19], what could not be done yet in our low volume unit.

Coming to an end we need to remember that minimal volume standards are set through the establishment of Centre of Excellence programs, demanding a facility volume of at least 80 qualifying bariatric procedures per year and an individual surgeon volume of at least 125 qualifying bariatric procedures in his/her lifetime, with at least 50 cases performed in the last 12 months [24]. On the one hand we support the implementation of these programs in bariatric surgery unit. Although knowing the situation in countries already developing bariatric centers (like Poland) we are afraid that these requirements can inhibit the establishment of new bariatric centers in the time when obesity is endemic.

\section{CONCLUSION}

The institutional learning process' stabilization point for LRYGB in a newly established bariatric center of the low volume is after 90th operation. LRYGB, which is carried out with a learning curve, does not affect the safety of the procedure in terms of intraoperative adverse events. 


\section{PIŚMIENNICTWO}

1. World Health Organization. Obesity and overweight. Fact sheet; http://www. who.int/mediacentre/ factsheets/fs311/en/ (dostęp: 21 grudnia 2018).

2. Eurostat. European Health Interview Survey; https://ec.europa.eu/eurostat/ statisticsexplained/index.php?title=Overweight_and_obesity_-_BMI_statistics (dostęp: 21 grudnia 2018).

3. Fruhbeck G., Toplak H., Woodward E., Yumuk V., Maislos M. et al.: Obesity: the gateway to ill health - an EASO position statement on a rising public health, clinical and scientific challenge in Europe. Obes Facts., 2013; 6(2): 117-120.

4. Flegal K.M., Kit B.K., Orpana H., Graubard B.I.: Association of all-cause mortality with overweight and obesity using standard body mass index categories: a systematic review and meta-analysis. Jama., 2013; 309(1): 71-82.

5. Jl C., Picot J., Loveman E., Aj C.: Surgery for obesity. Cochrane Database Syst Rev., 2009; 2009(2): CD003641.

6. Nguyen N.T., Goldman C., Rosenquist C.J. et al.: Laparoscopic versus open gastric bypass: a randomized study of outcomes, quality of life, and costs. Ann Surg., 2001; 234(3): 279-89. Omówienie wyników 289-291; http://www. pubmedcentral.nih.gov/articlerender.fcgi?artid=1422019\&tool=pmcentre$\mathrm{z} \&$ rend rtype $=$ abstract

7. Shin R.B.: Evaluation of the learning curve for laparoscopic Roux-en-Y gastric bypass surgery. Surg Obes Relat Dis., 2005; 1: 91-94.

8. Khan N., Abboudi H., Khan M.S., Dasgupta P., Ahmed K: Measuring the surgical "learning curve": methods, variables and competency. BJU Int, 2014; 113: 504-508. doi:10.1111/bju.12197.

9. Sánchez-Santos R., Estévez S., Tomé C., González S., Brox A. et al. : Training programs influence in the learning curve of laparoscopic gastric bypass for morbid obesity: a systematic review. Obes Surg., 2012; 22(1): 34-41.

10. Walinga A.B., van Mil S.R., Biter L.U., Cleffken B.I., van der Harst E.: A Stepwise Approach in Learning Surgical Residents a Roux-en-Y Gastric Bypass. Obes Surg., 2018 Oct 5. doi: 10.1007/s11695-018-3533-0.

11. Major P., Wysocki M., Pędziwiatr M., Pisarska M., Dworak J. et al.: Risk factors for complications of laparoscopic sleeve gastrectomy and laparoscopic Roux-en-Y gastric bypass. Int J Surg., 2017; 37: 71-78. https://doi.org/10. 1016/j. ijsu.2016.12.012.

12. Major P., Wysocki M., Torbicz G., Gajewska N., Dudek A. et al.: Risk factors for prolonged length of hospital stay and readmissions after laparoscopic sleeve gastrectomy and laparoscopic Roux-en-Y gastric bypass. Obes Surg., 2017; https://doi.org/10.1007/s11695-017-2844-x.
13. Matłok M., Pędziwiatr M., Major P., Kłęk S., Budzyński P. et al.: One hundred seventy-nine consecutive bariatric operations after introduction of protocol inspired by the principles of enhanced recovery after surgery $\left(\right.$ ERAS $\left.^{\circ}\right)$ in bariatric surgery. Med Sci Monit., 2015; 21:791-797. https://doi.org/10.12659/MSM.893297.

14. Dindo D., Demartines N., Clavien P.A.: Classification of surgical complications: a new proposal with evaluation in a cohort of 6336 patients and results of a survey. Ann Surg., 2004; 240(2): 205-213.

15. Shih-Chiang S., Chun-Yi T., Chien-Hung L., Yu-Yin L., Ta-Sen Y. et al.:: Learning curve of laparoscopic Roux-en-Y gastric bypass in an Asian low-volume bariatric unit. Asian J Surg., 2018; 41(2): 170-175. doi: 10.1016/j.asjsur.2016.11.007. Epub 2017 Jan 17.

16. Geubbels N., de Brauw L.M., Acherman Y.I., van de Laar A.W., Wouters M.W. et al.: The Preceding Surgeon Factor in Bariatric Surgery: a Positive Influence on the Learning Curve of Subsequent Surgeons. Obes Surg., 2015; 25(8): 1417-1424. doi: 10.1007/s11695-014-1538-x.

17. Oliak D., Ballantyne G.H., Weber P., Wasielewski A., Davies R.J. et al.: Laparoscopic Roux-en-Y gastric bypass: defining the learning curve. Surg Endosc., 2003; 17: 405e408.

18. Zevin B., Aggarwal R., Grantcharov T.P.: Simulation-based training and learning curves in laparoscopic Roux-en-Y gastric bypass. Br J Surg., 2012; 99: 887e895.

19. El-Kadre L., Tinoco A.C., Tinoco R.C., Aguiar L., Santos T.: Overcoming the learning curve of laparoscopic Roux-en-Y gastric bypass: a 12-year experience. Surg Obes Relat Dis., 2013; 9(6): 867-872. doi: 10.1016/j.soard.2013.01.020.

20. Sommer T., Larsen J.F., Raundahl U.: Eliminating learning curve-related morbidity in fast track laparoscopic Roux-en-Y gastric bypass. J Laparoendosc Adv Surg Tech A., 2011; 21(4): 307-312. doi: 10.1089/lap.2010.0569.

21. Søvik T.T., Aasheim E.T., Kristinsson J., Schou C.F., Diep L.M. et al.: Establishing Laparoscopic Roux-en-Y Gastric Bypass: Perioperative Outcome and Characteristics of the Learning Curve. Obes Surg., 2009; 19(2): 158-165. doi: 10.1007/s11695-008-9584-x.

22. Mammen J.M., Fischer D.R., Anderson A., James L.E., Nussbaum M.S. et al.: Learning styles vary among general surgery residents: analysis of 12 years of data. J Surg Educ., 2007; 64(6): 386-389. https://doi.org/10.1016/j.jsurg.2007.08. 005.

23. Quillin R.C., Pritts T.A., Hanseman D.J., Edwards M.J., Davis B.R.: How residents learn predicts success in surgical residency. J Surg Educ., 2013; 70(6): 725-730. https://doi.org/10.1016/j.jsurg.2013.09.016.

24. COEMBS Designation Requirements [Internet]: http://www.surgicalreview. org/wp content/uploads/COEMBSRequirements__Rev-02 2013.pdf.

$\begin{array}{llll}\text { Word count: } 4450 \quad \text { Page count: } 8 \quad \text { Tables: } 3 & \text { Figures: } 2 & \text { References: } 24\end{array}$

DOI:

10.5604/01.3001.0014.1513 Table of content: https://ppch.pl/issue/13166

Copyright: Some right reserved: Fundacja Polski Przegląd Chirurgiczny. Published by Index Copernicus Sp. z o.o.

Competing interests: The authors declare that they have no competing interests.

○ The content of the journal "Polish Journal of Surgery" is circulated on the basis of the Open Access which means free and limitless access to scientific data.

This material is available under the Creative Commons - Attribution 4.0 GB. The full terms of this license are available on: http://creativecommons.org/licenses/by-nc-sa/4.0/legalcode

Corresponding author: Jadwiga Dworak; 2nd Department of General Surgery, Jagiellonian University Medical College, Cracow, Poland; Phone: +48 1242482 00; E-mail: jadwigadworak@gmail.com

Cite this article as: Dworak J., Wysocki M., Rzepa A., Pedziwiatr M., Radkowiak D., Budzynski A., Major P.: Learning curve for laparoscopic Rouxen-Y gastric bypass based on the experience of a newly created bariatric center; Pol Przegl Chir 2020: 92 (4): 23-30 